\title{
Experimental Investigation on Heat Transfer and Pressure Drop in Double Helically Coiled Tube Heat Exchanger with MWCNT/Water Nanofluid
}

\author{
M. Chandrasekar ${ }^{1 \dagger}$ and P. C. Mukesh Kumar ${ }^{2}$ \\ ${ }^{1}$ Department of Mechanical Engineering, Chettinad College of Engineering and Technology, \\ Karur, Tamilnadu, 639114, India \\ ${ }^{2}$ Department of Mechanical Engineering, University College of Engineering, Dindigul, Tamilnadu 624 622, India
}

†Corresponding Author Email: chandrumechnano@gmail.com

(Received May 15, 2018; accepted July 18, 2018)

\begin{abstract}
In this experimental work, heat transfer and pressure drop analysis of a Double helically coiled tube heat exchanger by using Multi-walled carbon nanotube (MWCNT) /Water nanofluid as a coolant. The analysis is done under constant heat flux and turbulent flow condition. The double helically coiled tube heat exchanger (DHCTHX) is designed and fabricated. The MWCNT/water with $0.2 \% 0.4 \% \& 0.6 \%$ volume concentration nanofluids are prepared by using two-step method. The nanofluid prepared is characterized by using SEM (Scanning Electronic Microscope). Initially, hot water and cold water with 120,140,160\& 180LPH (liter per hour) of flow rates are tested. Secondly hot water and $0.2 \% 0.4 \% \& 0.6 \%$ volume concentration of MWCNT/water nanofluid with the same mass flow rates are tested. On comparing, the MWCNT nanofluids have better heat transfer rate than that of water. It is found that the heat transfer rate increases with increasing volume concentration of nanofluids. The maximum heat transfer rate obtained is at $0.6 \%$ volume concentration of nanofluids at the $120 \mathrm{LPH}$ mass flow rate at 1460 Dean Number. It is also studied that MWCNT /water nanofluid's overall heat transfer rate is $56 \%$ higher than water at $0.6 \%$ nanofluid at 1460 Dean Number. It is also found that the pressure drop of MWCNT/water $0.6 \%$ nanofluid is $49 \%$ higher than that of water at 1460 Dean number.
\end{abstract}

Keywords: MWCNT/water; Double Helically coiled tube heat exchangers; Nusselt number; Thermal conductivity; Secondary flow; Dean number.

\section{NOMENCLATURE}

$\begin{array}{ll}\text { A } & \text { surface area } \\ \text { cp } & \text { specific heat capacity } \\ \text { dii } & \text { inner diameter of inner coil } \\ \text { dio } & \text { outer diameter of inner coil } \\ \text { doi } & \text { inner diameter of outer coil } \\ \text { doo } & \text { outer diameter of outer coil } \\ \mathrm{De} & \text { Dean number } \\ \mathrm{h} & \text { convective heat transfer coefficient } \\ \mathrm{k} & \text { thermal conductivity } \\ \mathrm{L} & \text { effective length of tube } \\ \mathrm{m} & \text { mass flow rate } \\ \mathrm{Nu} & \text { Nusselt number } \\ \mathrm{Q} & \text { heat transfer rate }\end{array}$

\section{INTRODUCTION}

Nowadays heat exchanger design and existing coolants heat transfer performance and limited due

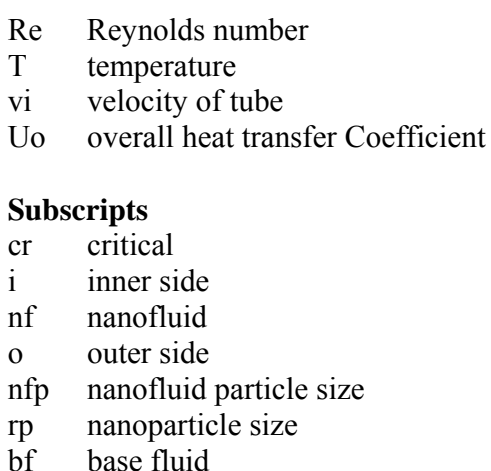

to technological development. In order to improve the thermal performances of existing coolants, the newly developed Nanofluids are currently being investigated. Bai et al.(1999) studied that turbulent 
heat exchanger from flat helical coils. It is noted that heat exchanger behavior is increased when coil pitch is increased compared with a straight tube. It is the extensive limit layer that is shed off into the focal point of the tube by the auxiliary stream that expands the heat exchanger coefficient, and this impact diminishes with expanding Reynolds number (Bai et al., 1999). The nearby heat exchanger coefficient on the external divider can be 3 to 4 times that of the inward divider. They built up a relationship of the Nusselt number as an element of the area on the fringe. They additionally built up a Nusselt number relationship; be that as it may, it didn't contain the Dean number as just a single size of the loop was utilized as a part of the trial. Correlations for the heat exchanger coefficients between straight tubes and helically curled tubes drenched in a water shower were performed. Findings demonstrated that the heat exchanger coefficient were more prominent in the helically snaked framework.

Ferng et al. (2012) worked out the numerical work in a helically curled heat exchanger. The numerical examination was engaged to anticipate the impacts of Dean number and pitch size of the tube on the heat and water driven qualities of a helical tube heat exchanger. They had considered three Dean numbers and four sizes of a pitch for their study. The turbulent wake around the back of a snaked tube, the optional stream inside the tube, and the creating stream and heat exchanger practices from the passage area, and so on was examined by them. Genic Srbislav et al. (2012) observed that the experimental work predict the exhibitions of heat exchangers with the helical tube. In their work, they had displayed the aftereffects of heat execution estimations on heat exchangers with concentric helical loops. It was discovered that the shell-side heat exchanger coefficient was influenced by the geometric parameters. The winding point, spiral pitch, and hub pitch are the geometric parameters which influence the heat exchanger coefficient. From the outcomes, it was presumed that the shellside heat exchanger coefficient depends on shell side water powered distance across. The last type of shell-side heat exchanger relationship proposed by Srbislav et al. (in which Nusselt and Reynolds numbers depend on water-powered measurement) is given by, $\mathrm{Nu}=0: 50 \operatorname{Re} 0: 55 \operatorname{Pr} 1 / 3(/ \mathrm{w}) .14$.

It was carried out the trial think about on relentless state normal convection heat exchange from helical coil tubes. Water was utilized as a shower fluid with no blending and air was utilized as a coolant liquid. A straight copper container of $13 \mathrm{~mm} \mathrm{ID,} 14 \mathrm{~mm}$ OD and $3 \mathrm{~m}$ length was twisting to create the helical loop. Two loops are utilized as a part of this investigation has an ebb and flow proportion of 0.1101 and 0.0942.The information were corresponded utilizing tube breadth as the trademark length. The outcomes demonstrate that the general heat exchanger coefficient and weight drop are expanded when the stream rate of coolant and flow proportion increment. It is studied from the literature review that very limited research work is reported on DTHCHE by using nanofluids. Therefore in this research work, heat transfer performance and pumping power requirement of DTHCHE by using MWCNT/water nanofluids proposed.

It was concluded that the greatest improvement of inner heat transfer coefficient was observed by helically coiled tube with $\mathrm{Al} 2 \mathrm{O} 3$ / water nanofluid then the circulation of nanofluid in a helical tube with a flow of laminar and increase the heat transfer coefficient and decreasing the friction factor by increasing nanofluid volume concentration. In secondary flow formation of coiled tubes with no undesirable impression of presence of nanoparticles. It was observed that there is no changes in parallel flow and counter flow conditions in overall heat transfer coefficient .So nanofluid passes through the helical coiled tube heat exchanger to increase heat transfer. It is observed that most of the existing investigations have been done on the double helically coiled tube have used water as the heat transfer fluid. Moreover, many research works have been carried out by changing the coiled tube dimensions by using water as target fluids. The research works on double helically coiled tube heat exchanger handling MWCNT/water Nanofluid is limited. Therefore, In this experimental work, heat transfer analysis and pressure drop of double helically coiled tube heat exchanger are investigated by using different volume concentration of MWCNT /Water nanofluids as a coolant. Srinivasan (2017) studied and analysed about the missile with grid fins and the effect on flow drag using ANSYS. Godwin (2017) and Lakshmanan (2017) investigated about the optimum parameters for obtaining the best performance using alternate fuels of IC engines working under the current cooling system using Nanofluids.

\section{MATERIALS AND METHODS}

\subsection{Particulars of MWCNT Nanostructures}

The Particulars of MWCNT are given by the supplier as mentioned in table 1 . The SEM image shows that the CNTs are uniformly dispersed in the base fluids figure.2. Prasher (2006) and Timofeeva (2009) reported that The thermal conductivity and viscosity are found the formulas and experimentally find the ' $k$ ' and ' $\mu$ ' values. The values are compared, there is no major difference in that ' $\mathrm{k}$ ' and ' $\mu$ ' theoretical values

Table 1 Properties of MWCNT

\begin{tabular}{|c|c|c|}
\hline $\begin{array}{c}\text { Volume } \\
\text { concentration } \\
\text { of MWCNT } \\
(\%)\end{array}$ & $\begin{array}{c}\text { Thermal } \\
\text { conductivity, } K \\
(\mathrm{~W} \mathrm{~m}-1 \mathrm{~K}-1)\end{array}$ & $\begin{array}{c}\text { Viscosity, } \\
(\mathrm{Ns} \mathrm{m}-2)\end{array}$ \\
\hline 0.2 & 0.7136 & $1.5255^{*} 10^{-3}$ \\
\hline 0.4 & 0.8125 & $2.044^{*} 10^{-3}$ \\
\hline 0.6 & 0.888 & $2.5652 * 10^{-3}$ \\
\hline
\end{tabular}

\subsection{Preparation of MWCNT/water Nanofluid}

The MWCNT nanoparticles were purchased from 
Nanostructured \& Amorphous Materials, Inc. Houston, TEXAS, and the USA. The MWCNT nanoparticles considered by UV- visible spectroscopy.The average CNT dimensions were found to be between $50-80 . \mathrm{nm}$ (the error limit is $\pm 5 \mathrm{~nm}$ ) using Zeta potential of nanoparticles Fig. 1 . In this research MWCNT, water-based nanofluid is prepared by two methods. Because two-step method is superior for nanostructure and this two-step method gives greater stability with a small amount of agglomeration Ghadimi (2011) The MWCNT water-based nanofluids have been synthesized at $0.2 \%, 0.4 \%, 0.6 \%$, volume concentration and morphologically characterized by nanofluid attained by the help of (SEM) are shown Fig. 2. SEM image visibly shown the MWCNT formation is concentric tube-like hollow tubes with continuous sheets exactly similar to the MWCNT alignment. From the Fig 2. the nanostructures are stable without any agglomeration and homogeneously spread. And also detected there is not at all sedimentation of nanotubes after 30 days of the immobile situation of nano fluid.

Ruthven (1971) stated that the secondary flow mete out the greater heat and velocity profiles reaches the maximum level compare than the straight tubes any type of flow conditions (Laminar \& Turbulent). Also, they have reported some pressure drop occurred in the secondary formation of tubes. Jayakumar et al (2010) have recommended that any correlation for estimation of Nusselt number for the helically coiled tube is included the helical coil parameters pitch with circle geometrical dimensions apart from flow limitations with basic properties.

Saidur et al. reported that industrial heat exchanger is effectively working by implementing the nanofluid as a heat transfer medium fluid. Huminic (2011) concluded heat transfer coefficient of the base fluid and Nano fluid increasing the mass flow rate as well as Dean Number also simultaneously increased. Hashemi (2012) reported that the heat transfer results are superior to the straight tube and $\mathrm{CuO} /$ oil Nano fluid generates the greater heat transfer and nominal pressure drop occurred. Their innovation idea of the parameter that is "performance index" to consider heat transfer and pressure drop characteristics at the similar period. Kumaresan (2012) delivered to SDBS solution-soap oil (Sodium dodecyl benzene sulfonates) is a surfactant to maintaining the long-term stability of nanotubes deionized water. Venkatesh et al (2016) studied the flow of heat and fluid in solar air heater using Computational Fluid Dynamics (CFD). The predicted temperature results were observed within a deviation of $\pm 10.64 \%$.

Jorge (2009) found that the extreme heat transfer improvement is achieved in nearly 45 minutes in an ultrasonic vibrator. Ultrasonic vibration results and SEM results are related to heat transfer enhancements of MWCNT nano fluids. The required quantity of MWCNT nanoparticles are dispersion into deionized water with the Ultrasonic vibrator (Toshiba, India) making Ultrasonic pulses $100 \mathrm{~W}$ at $40 \pm 5 \mathrm{kHz}$ and run the Ultrasonic vibrator for nonstop four hours to produce the nominal dispersion of nanoparticles as well as the steadystate condition of MWCNT nanoparticles with the suspension of nanoparticles prepared. The 0.1 \%volume concentration of nanoparticles of Sodium dodecyl benzene sulfonates (SDBS-soap oil) Surfactant is mixed with deionized water to produce the improved stability of nanofluids. Pak (1998) revealed that the adding the MWCNT nanoparticles is gives the best agglomeration and increase the viscosity of MWCNT nanofluid as well as the increase the overturn the thermal conductivity of nanofluid.

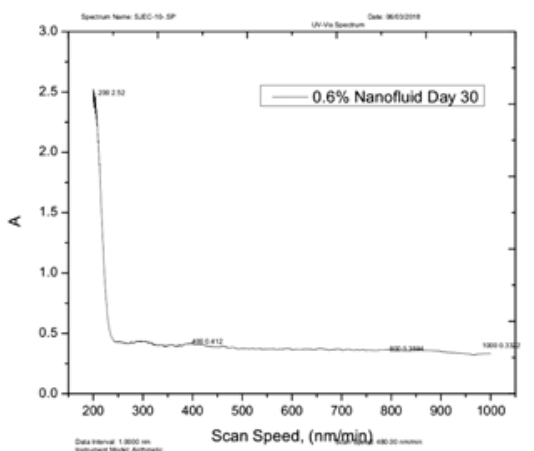

Fig. 1. UV- visible spectroscopy of MWCNT nanoparticles

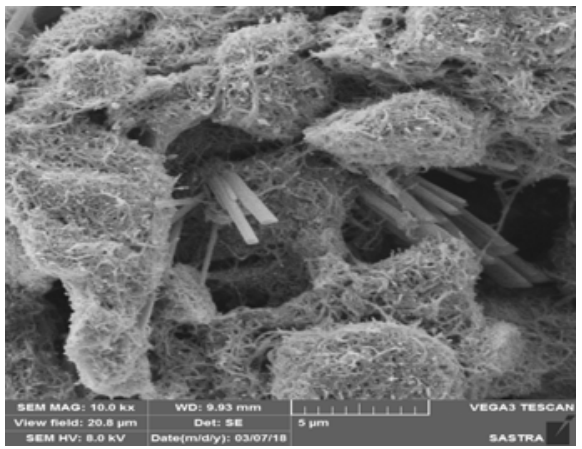

Fig. 2. SEM image of MWCNT/water nanofluid.

\section{DOUBLE TUBE HELICALLY COILED TUBE HEAT EXCHANGER (DTHCTHX)}

Xin (1996) conveyed helically coils are used as a heat exchanger in Nuclear power plants, foodstuff processing units, refrigeration units and recovery plants. Naphon reviewed that Helically coiled tube heat exchangers and nanofluids are submissive heat transfer standard. Vimal (2008) reported that shell regions gain an only small amount of heat transfer transferred. In order to replace shell to double tube helically coiled heat exchangers for better performance of heat transfer rate is increased.

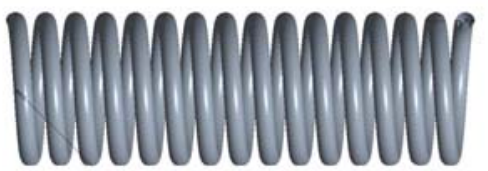

Fig. 3. Double helically coiled tube coil

Shah (1987) recommended that double tube helically coiled will be resolved by either the 
heating or refrigeration are delivered by a secondary fluid in part of the wall. Double tube helically coil is maintained constant wall flux conditions. Rennie (2005) concluded that heat transfer in a double helically coiled tube heat exchangers fixed of one concentric circle. When the coil mean diameter increase at the time that heat exchanger gains the better overall heat transfer coefficient.

\section{EXPERIMENTAL SETUP}

Figure 4. illustrates the schematic diagram of the experimental setup. The experimental set-up consists Double helically coiled tube. The outer tube is used to hot water. Double helically coiled tube inner tube uses MWCNT / water nano fluid. The outer tube side flow and coiled tube side flow are in counter flow configuration. Outer tube side loop is connected with storage vessel size $30 \mathrm{~cm} \mathrm{x}$ $25 \mathrm{~cm} \times 25 \mathrm{~cm}$, with $2 \mathrm{KW}$ capacity, hot water pump with the thermostat. Double coiled tube loop side is connected with a monoblock pump with $0.5 \mathrm{hp}$ power, flow control valve fixed in the tube side, test section, cooling unit, and storage tank of five-liter capacity.

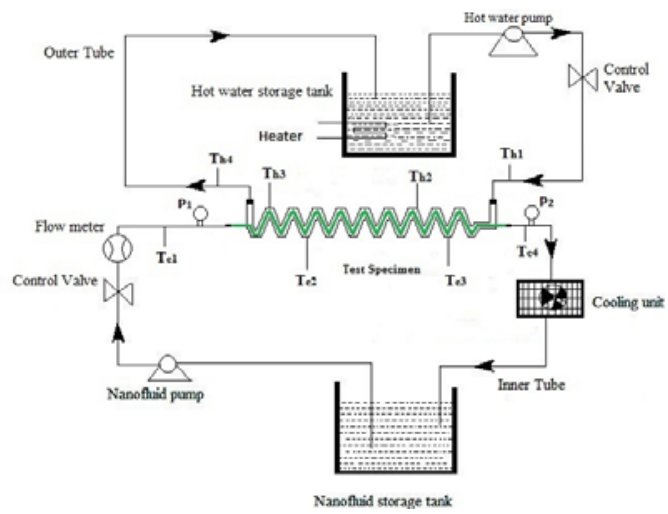

Fig. 4. Block diagram of the experimental arrangement

The Double helically coiled tube is made by winding a straight copper tube on the wooden cylindrical template. Fine sand has filled the tube to not have the distortion of the inner surface. The Double helically coiled tube is made up of copper. The thermostat is used to maintain the temperature of hot water in outer tube storage vessel. Four Ktype thermocouples of $0.09^{\circ} \mathrm{C}$ accuracy were used to measure the inlet and outlet temperature of the Double helically coiled side. Four K -type thermocouple of $0.09^{\circ} \mathrm{C}$ were fitted on the outer surface of coiled to measure the outer tube temperatures.

The thermocouples were fitted in the metal paste to avoid leakage. The calming section is provided in the Double helically coiled tube to avoid the entrance effort. The pressure gauge is used to measure the pressure inlet and outlet of the nanofluid inner tube. The outer tube is insulated with pure cotton threads to maintain constant heat flux method. A flow control valve is fitted in the flow pipe to control the flow, radiator with an attachment fan is used to cool the hot nanofluids. Dean (1927) has suggested the dimensionless number is called as Dean Number, it is related to the inertia and centrifugal force in flow through a bent pipe. Dean number dealings with the secondary flow.

Before using the nanofluid water is circulated to check the experimental setup and its fittings and their leakages and confirm all equipment functions.

\subsection{Experimental Procedure}

The Double helically coiled angle is maintained constant throughout the test. Hot water and cold water are allowed to outer tube and tube side respectively under counter flow condition. The pump is operated when the outer tube side attains the required steady state temperature. The outer tube side fluid temperature is controlled by the thermostat. The corresponding temperatures are noted at the outer tube and Double helically coiled tube side. The nanofluid at $0.2 \% 0.4 \%$ and $0.6 \%$ volume concentration are circulated through tube side. Hot water is circulated to the outer tube side. Flow rate on the outer tube side is kept constant $(150 \mathrm{LPH})$ and flow rate on tube side is varied. The temperatures are measured after getting steady state condition. The flow rates are recorded manually by collecting the fluid with the measuring Jar and stopwatch. The tests were conducted in the range of $481<\mathrm{De}<2300$ underflow condition. The range of nanofluid flow rate is in the range of $120-180$ LPH. The pressure drop is recorded by using the Pressure gauge. Total nanoparticles are measured by assessing the tube side Nusselt number are exposed to uncertainties some of the mistakes found in the measuring techniques. Table 2 and 3 represents the physical properties of nanoparticle and thermal properties of nanofluids.

Table 2 Physical Parameters of MWCNT Nanoparticles

\begin{tabular}{|c|c|}
\hline Material Parameters & MWCNT \\
\hline True Density, $\mathrm{g} / \mathrm{cm}^{3}$ & 2.1 \\
\hline Bulk Density, $\mathrm{g} / \mathrm{cm}^{3}$ & 0.18 \\
\hline Length, $\mu \mathrm{m}$ & $10-20$ \\
\hline Outer diameter, $\mathrm{nm}$ & $50-80$ \\
\hline Inner diameter, $\mathrm{nm}$ & $5-15$ \\
\hline
\end{tabular}

Table 3 Thermo physical Properties of Water And 0.6\% Vol. Con Nano fluid

\begin{tabular}{|c|c|c|}
\hline Materials Properties & Water & MWCNT \\
\hline Density (kg/m3) & 997 & 1660 \\
\hline $\begin{array}{c}\text { Specific heat } \\
\text { Capacity (J/kg K) }\end{array}$ & 4187 & 2310 \\
\hline $\begin{array}{c}\text { Thermal } \\
\text { Conductivity } \\
\text { (W/mK) }\end{array}$ & 0.613 & 0.888 \\
\hline $\begin{array}{c}\text { Dynamic } \\
\text { Viscosity (cP) }\end{array}$ & 0.8 & 2.562 \\
\hline
\end{tabular}




\subsection{Data Processing}

Finding the heat transfer for base fluid and MWCNT nanofluids are predictable from equations (1) and (2). Average heat transfer only used for this experimental work.Heat transfer coefficient of an inner and overall helically coiled tubes are found the from equations .(3) and (4).

$\mathrm{Q}_{\mathrm{bf}}=\mathrm{M}_{\mathrm{bf}} * \mathrm{C}_{\mathrm{pbf}}\left(\mathrm{T}_{\text {inlet }}-\mathrm{T}_{\text {outlet }}\right) * 1000$

$\mathrm{Q}_{\mathrm{nf}}=\mathrm{M}_{\mathrm{nf}} * \mathrm{C}_{\mathrm{pnf}}\left(\mathrm{T}_{\text {inlet }}-\mathrm{T}_{\text {outlet }}\right) * 1000$

$U_{o}=\frac{Q}{A_{o} \operatorname{lm} t d}$

$h_{i}=\frac{Q_{c}}{A_{i o}\left(T_{2}-T_{1}\right)}$

\section{RESULTS}

\subsection{Heat Transfer of MWCNT/Water Nano Fluids}

Figure 5.shows that the increasing overall heat transfer coefficient with increasing tube side Dean number and particle volume concentration. The enhancement of the maximum overall heat transfer coefficient is $50 \%$ at $0.6 \%$ volume concentration at tube side Dean number of 2300. It is due to maximum heat transfer and reducing the temperature drop between the nanofluid in inner coil tube.

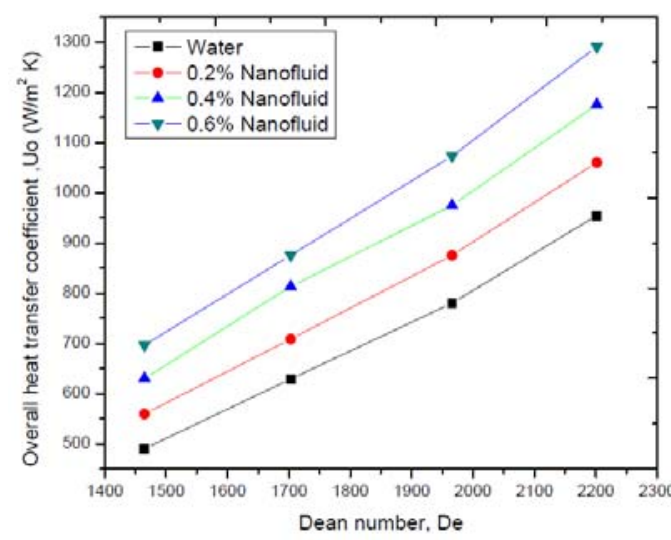

Fig. 5. Deviation of overall heat transfer coefficient with tube side Dean Number.

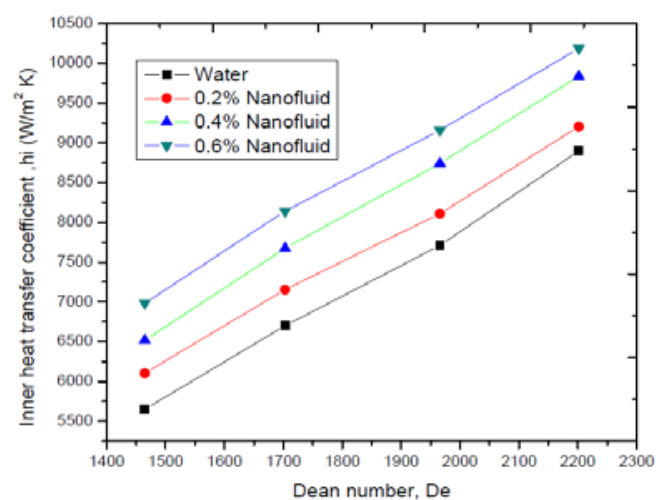

Fig. 6. Deviation of inner heat transfer coefficient with tube side Dean Number.

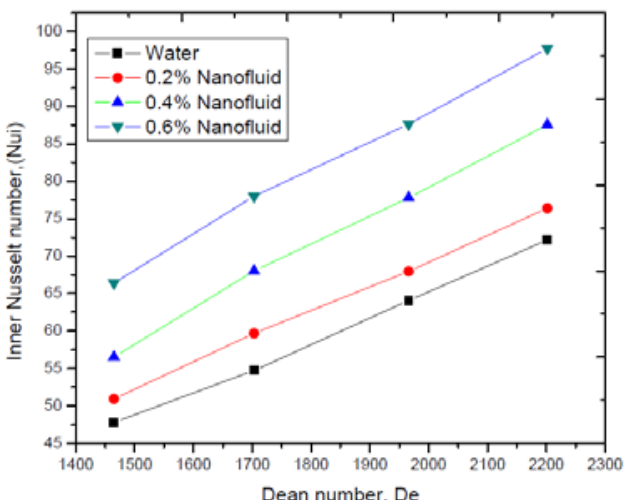

Fig. 7. Deviation of inner Nusselt number with tube side Dean Number.

Figure 6.shows that the effect of change of particle volume concentration on inner heat transfer coefficient. It is studied that the tube side heat transfer coefficient increases with respect to the Dean number. The enhancement of tube side inner heat transfer coefficient were found to be $30 \%$, $58 \%$, and $68 \%$ higher than the water at $0.2 \%, 0.4 \%$, and $0.6 \% \mathrm{MWCNT} /$ water nanofluids respectively. It is found that heat transfer coefficient is improved even at $0.1 \%$ particle volume concentration. This is because of the reduction in the temperature difference between the wall and the bulk nanofluids. The reduction of wall temperature occurs when the dispersed and suspended MWCNT impinges the bent surface as helically coiled shape.

Figure 7 describes the enhancement of experimental Nusselt number by varying tube side Dean number and particle volume concentration. The enhancements of tube side experimental Nusselt numbers were found to be $44 \%, 62 \%$ and $73 \%$ at $0.2 \%, 0.4 \%$ and $0.6 \% \mathrm{MWCNT} /$ water nanofluids, respectively when compared to water. The enhancement may due to thorough mixing of fluid particles and CNTs, and Brownian motion of CNTs. It means that the formation of secondary is not affected when MWCNT is allowed in the double helically coiled tube.

\subsection{Effect of Pressure Drop}

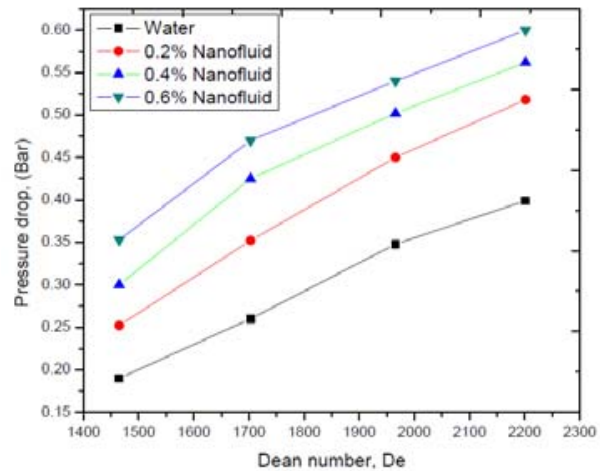

Fig. 8. Deviation of pressure drop with tube side Dean Number

Figure 8 shows that the pressure drop increases with increasing particle volume concentration and Dean 
Number. The pressure drop of $0.2 \%, 0.4 \%$ and $0.6 \%$ are $28 \%, 56 \%$ and $84 \%$ higher than water respectively. This is due to increase in viscosity when increasing particle volume concentration. It is found that pressure drop at $0.6 \%$ nanofluid and at maximum Dean Number is the highest.

\section{ConClusion}

In this experimental investigation, Turbulent $(480<$ De $<2300$ ) heat transfer and experimental pressure drop of the double helically coiled tube with MWCNT/water nanofluid at $0.2 \%, 0.4 \%$, and $0.6 \%$ particle volume concentration were tested. The nanofluids have been prepared by a two-step method. The heat transfer and pressure drop of water and nanofluids are compared. It is studied that the heat transfer coefficient increase with increasing the particle concentration. The maximum enhancement of overall heat transfer coefficient and Nusselt number were found to be $50 \%, 56 \%$, and $60 \%$ respectively higher than water at $0.6 \%$ volume concentration. These enhancements are due to the higher thermal conductivity of nanofluid, through a mixing of nanofluids, and easy movement of a nanoparticle. Further, it is observed that the presence of CNTs does not lead to the formation of very strong secondary flow in a coiled tube. It is also noted that the pressure drop increases while increasing particle volume concentration. The pressure drop is $84 \%$. higher than water at $0.6 \%$ volume concentration. This pressure drop increase is due to increase in viscosity when the particle volume concentration is increased. Therefore, the MWCNT/ water nanofluids are the suitable cooling fluids in double helically coiled tube heat exchanger with considerable pressure drop. Therefore the MWCNT nanofluid has the potential use of a DTHCHE and the replace existing coolants.

\section{REFERENCES}

Bai, B. F., L. Guo, Z. Feng, and X. Chen (1999). Turbulent heat transfer in a horizontally coiled tube, Heat Transfer Asian Res. 28, 395-403.

Dean, W. R. (1927) Note on the motion of fluid in a curved pipe, Philos. Mag 4, 208-223.

Ferng, Y. M., W. C. Lin, and C. C. Chieng (2012). Numerically Investigated Effects of Different Dean Number and Pitch Size on Flow and Heat Transfer Characteristics in a Helically Coil Tube Heat Exchanger, Applied Thermal Engineering 36, 378-385.

Genic, B., Jacimovic M., Jaric S., Budimir J., Dobrnjac (2012). Research on the shell-side Thermal performances of heat exchangers with helical tube coils, International Journal of Heat and Mass Transfer 55, 4295-4300.

Ghadimi, A. (2011). A review of nanofluid stability properties and characterization in stationary conditions, International Journal of Heat and Mass Transfer 54, 4051-4068.
Godwin Antony, A., S. Dinesh, K. Rajaguru, V. Vijayan (2017). Analysis and Optimization of Performance Parameters in Computerized I.C. Engine Using Diesel Blended with Linseed Oil and Leishmaan's Solution, Mechanics and Mechanical Engineering 21(2), 193-205.

Hashemi, (2012). An empirical study on heat transfer and pressure drop characteristics of $\mathrm{CuO}$-base oil nanofluid flow in a horizontal helically coiled tube under constant heat flux", Int. Communications in Heat and Mass Transfer 39, 144-151.

Huminic, A. (2011). Heat transfer characteristics in double tube helical heat exchangers using nanofluids, Int. Journal of Heat and Mass Transfer 54, 4280-4287.

Jayakumar, M., I. Mandala, and V. Vijayan (2010). CFD analysis of single-phase flows inside helically coiled tubes, Computers and Chemical Engineering 34, 430-446.

Jorge, P., L. Alvarado, C. Marsh, T. A. Carlson, D. A. Kessler and K. Annamalai (2009). An experimental study on the effect of ultrasonication on viscosity and heat transfer performance of multi-wall carbon nanotubebased aqueous nanofluids, International Journal of Heat and Mass Transfer 52, 5090-5101.

Kumar, V., B. Faizee, M., Mridha, K. D. P. Nigam (2008). Numerical studies of a tube-in-tube helically coiled heat exchanger, Chemical Engineering and Processing 47, 2287-2295.

Kumaresan, V. and R. Velraj (2012). Experimental investigation of the thermo Physical properties of water - ethylene glycol mixture based CNT nanofluids, Thermochimica Acta 545, 180-186.

Lakshmanan, P., P. Kaliyappan, M. Ranjithkumar, K. Aravinth, D. Vakkachan, C. Moorthy and S. Kumar (2017). An Experimental Investigation to Study the Performance and Emission Characteristics of Chicken Fat Oil Fuelled DI Diesel Engine, Journal of Applied Fluid Mechanics 10, Special Issue, 85-91

Naphon, P. and S. Wongwises (2006). A review of flow and heat transfer characteristics in curved tubes, J. Renew. Sustain. Energy Rev. 10, 463490.

Pak, B. C. and Cho, Y. L. (1998). Hydrodynamic and heat transfer study of Dispersed fluids with submicron metallic oxide particles, Exp. Heat Transfer 11, 151-170.

Prasher, R. (2006). Measurements of nanofluid viscosity and its implications thermal applications, Appl. Phys. Lett. 89, 133108.

Rennie, T. J. and V. G. S. Raghavan (2005). Experimental studies of a double pipe helical heat exchangers, Exp. Thermal Fluid Sci. 29, 919-924. 
M. Chandrasekar and P. C. Mukesh Kumar/ JAFM, Vol. 11, Special Issue, pp. 23-29, 2018.

Ruthven, D. M. (1971). The residence time distribution for ideal laminar flow in a helical tube, Chemical engineering Science 2, 11131121.

Shah, R. K. and S. D. Joshi (1987). Convective heat transfer in curved ducts, in: Handbook of singlephase convective heat transfer, Wiley, New York.

Srinivasan, R., V. Vijayan and K. Sridhar (2017). Computational Fluid Dynamic Analysis of Missile with Grid Fins. Journal of Applied
Fluid Mechanics 10, Special Issue 33-39.

Timofeeva, E. V. (2009). Particle shape effect on thermo physical properties alumina nanofluids. J. Appl. Phys. 106, 014304.

Venkatesh, R. and V. Vijayan (2016). Performance Evaluation of Multipurpose Solar Heating System, Mechanics and Mechanical Engineering 20(4), 359-370.

Xin, R. C. and M. A. Ebadian (1996). Natural convection heat transfer from helicoidal pipes, J. Thermophys. Heat Transfer 10, 297-302. 